\title{
Konaklama İşletmelerinde Örgüt Kültürünün Çalışılan Birime Göre Değerlendirilmesi: Güneydoğu Anadolu'da Bir Araştırma
}

\section{Evaluation of Accomodation Businesses' Organizational Culture According to the Department: A Research in Southeast Anatolia}

Çağdaş Ertaş a,*

${ }^{a}$ Dr. Öğr. Üyesi, Şırnak Üniversitesi, Turizm ve Otel İşletmeciliği Yüksekokulu, Turizm İşletmeciliği Bölümü, 73000, Şırnak/Türkiye. ORCID: 0000-0001-9641-8054

\section{MAKALE BİLGİSİ}

\section{Makale Geçmişi:}

Başvuru tarihi: 08 Nisan 2018

Düzeltme tarihi: 12 Temmuz 2018

Kabul tarihi: 09 Ağustos 2018

\section{Anahtar Kelimeler:}

Konaklama İşletmeleri

Örgüt Kültürü

Güneydoğu Anadolu

\section{ARTICLE INFO}

\section{Article history:}

\section{Received April 08, 2018}

Received in revised form July 12, 2018

Accepted August 09, 2018

\section{Keywords:}

Accomodation Businesses

Organizational Culture

Southeast Anatolia
ÖZ

$\mathrm{Bu}$ araştırmanın amacı, konaklama işletmeleri çalışanlarının örgüt kültürü algısını ve bu algının çalışılan birime göre farklılık gösterip göstermediğini tespit ederek, turizm yazınına ve konaklama işletmeleri yöneticilerine katkı sunmaktır. Araştırmanın ana kütlesi, Güneydoğu Anadolu Bölgesi'ndeki 5 yıldızlı otellerde çalışanlardır. Araştırmada veri toplama aracı olarak anket kullanılmıştır. Verilerin 20 Kasım 2017-15 Mart 2018'de toplandığı araştırmaya 246 kişi katılmıştır. Veri analizinde, açıklayıcı faktör analizi ve tek yönlü ANOVA testi kullanılmıştır. Açıklayıcı faktör analizi sonucunda, "bürokratik", "toplumcu" ve "yenilikçi” olmak üzere üç boyut tespit edilmiştir. Araştırma bulgularına göre, bu araştırma kapsamındaki çalışanlar, toplumcu ve yenilikçi kültüre kıyasla, bürokratik örgüt kültürüne daha yüksek ortalama vermiştir. Tek yönlü ANOVA testi sonucunda ise örgüt kültürü algısının çalışılan birime göre anlamlı bir farklılık göstermediği tespit edilmiştir.

\begin{abstract}
A B S T R ACT
The purpose of this research is to contribute to the tourism literature and hotel managers by determining the perception of the organizational culture of the hotel employees and whether this perception differs according to the department. The population of the research are employees working in 5-star hotels in Southeastern Anatolia. Questionnaire was used as data collection tool in the research. The data were collected between 20 November 2017-15 March 2018 and 246 people participated in the research. In the data analysis, exploratory factor analysis and one way ANOVA test were used. As a result of explanatory factor analysis, three dimensions were identified as "bureaucratic", "community" and "innovative". According to research findings, the average of bureaucratic culture is higher. As a result of the one-way ANOVA test, it was found the perception of organizational culture did not show any significant difference according to the department.
\end{abstract}

\section{Giriş}

Konaklama işletmelerinin birçok birimden oluşması, çok sayıda kişinin bir arada çalışmasını gerekli kılmaktadır (Akgündüz vd., 2015: 516). Birçok kişiyle bir arada çalışmak ise, çalışanlarda bazı istenmeyen davranışlara sebep olabilmektedir (Sünnetçioğlu vd., 2014: 18). Örneğin bazı çalışanlar, ekip halinde çalıştıklarında, tek başına çalıştığından daha az çaba gösterebilmektedir (Kanten, 2014: 13). $\mathrm{Bu}$ durum ise, ekip içindeki diğer bireylerin motivasyonunu bozabilmektedir. Bazı çalışanların ben odaklı bir kültüre sahip olmasından dolayı ekip çalışmasına uyum sağlayamaması (Hofstede vd., 2010: 124) da, söz konusu istenmeyen davranışlara örnek olarak gösterilebilir. Oysa konaklama işletmelerinde birçok işin ekip çalışmasını gerektirdiği, bilinen bir gerçektir. Bahse konu örnekler ve bunlara benzer davranışların önlenmesindeki en etkili faktörlerden biri ise örgütün sahip olduğu kültürüdür. Örgüt üyelerinin örgütün bir parçası olması ise örgütün kültürünü öğrenmesinden geçmektedir (Tütüncü ve Akgündüz, 2012: 60). Çalışanlar örgütün kültürünü benimsediğinde, en azından örgüt içinde, kendi kültüründen sıyrılıp örgütün sahip olduğu kültüre göre davranacaktır. Nitekim örgüt kültürü, çalışanların örgüt içindeki düşünce ve davranışlarını

\footnotetext{
* Sorumlu yazar/Corresponding author.

e-posta: ertascagdas@hotmail.com
} 
biçimlendirmektedir (Barutçugil, 2004: 101). Çalışanlara aynı değerleri aşılamayı amaçlayan örgüt kültürü sayesinde çalışanlar, örgüt amaçları doğrultusunda hareket edecek ve ortak bir paydada buluşacaktır (Diker, 2014: 152). Öte yandan, örgüt kültürü örgütsel yaşamı etkileyen önemli bir unsurdur (Polat ve Meyda, 2011: 153). Hepsinden önce, bir örgütün yerleşmiş bir kültürünün olması, çalışanlarına verdiği değerin bir göstergesidir (Köse, 2014: 9).

Yukarıda verilen kısa bilgiler 1şı̆̆ında, örgütlerin kültürlerinin tespit edilmesi ve söz konusu kültürün örgüt çalışanları açısından nasıl algılandığı önem arz etmektedir. Buna ek olarak, bir örgütün kültürünü örgütün farklı birimlerinde çalışan bireyler farklı algılayabilmektedir. Zira birim yöneticilerinin çalışanlarıyla ilişkisi gibi unsurlar, örgüt kültürünün algılanmasında da önemli etkide bulunabilecektir. Dolayısıyla örgütün kültürünün çalışanları tarafından nasıl algılandığının yanında, bu algının birimlere göre farklılık gösterip göstermediğini incelemek de bir o kadar önem taşımaktadır. Örgüt kültürüne dönük yapılan yazın incelemesi sonucunda, bu yönde sınırlı sayıda araştırmaya rastlanmıştır. Ayrıca yine aynı alan yazın incelemesinde, Güneydoğu Anadolu Bölgesi'ndeki turizm işletmelerinde yapılmış araştırma sayısının yetersiz düzeyde olduğu dikkati çekmiştir. Alan yazındaki bu eksikliklerden hareketle, bu çalışmada, Türkiye'de hizmet sektöründe önemli bir rol oynayan konaklama işletmelerinin örgüt kültürünün çalışanları tarafından nasıl algılandığı ve çalışılan birime göre bir farklılık gösterip göstermediği incelenmiştir. Böylece, turizm yazınına ve konaklama işletmeleri yöneticilerine katkı sunmak amaçlanmaktadır. $\mathrm{Bu}$ amaç doğrultusunda, bu araştırmada iki temel soru yanıtlanmaya çalışılmıştır.

(i) Konaklama işletmeleri çalışanlarının örgüt kültürü alg1sı ne durumdadır?

(ii) Konaklama işletmeleri çalışanlarının örgüt kültürü algısı, çalışılan birime göre anlamlı bir farklılık göstermekte midir?

\section{2. Örgüt Kültürü Kavramı ve Boyutları}

Örgüt kültürünün farklı disiplinler tarafından çalışılmış olması, örgüt kültürüne ilişkin çok sayıda tanımlamanın yapılmasına neden olmuştur (Durğun, 2006: 114). Çünkü her disiplin, kavramı kendi bakış açısına göre yorumlamış, dolayısıyla evrensel bir tanım geliştirmek mümkün olmamıştır (Köse, 2014: 7). Öyle ki daha 1989 yılında yapılmış bir çalışma sonucunda, örgüt kültürünü tanımlamak için 70'in üzerinde farklı kelime ya da cümle kullanıldığı tespit edilmiştir (Škerlavaj vd., 2010: 6391). Aradan geçen yaklaşık 30 yıl göz önünde bulundurulduğunda, bu sayının daha da artmış olması yüksek ihtimaldir.

Örgüt kültürüne dönük evrensel bir tamımda bulunmak mümkün olmasa da, bazı ortak özelliklerden bahsedilebilir. Örneğin Wiener (1988: 534), birçok araştırmacının "paylaşılan değerlerin" örgüt kültürünün tanımlanmasında çok önemli bir faktör olduğu konusunda hemfikir olduğunu belirtmektedir. Örgüt kültürünün özünü de, söz konusu bu değerler oluşturmaktadır (Zahedipour ve Haghighi, 2015: 118). Ayrıca, yazındaki örgüt kültürü tanımları (Pettigrew, 1979; Schwartz ve Stanley, 1981; Smircich, 1983; Cameron ve Quinn, 1999; Hartmann, 2006 gibi) derinlemesine incelendiğinde, hemen hemen bütün tanımlarda "değer", "varsayım" ya da "beklenti" kavramlarının geçtiği dikkati çekmektedir. Örgüt kültürü tanımlarında dikkat çeken bir başka husus, örgüt kültürünün örgüt üyelerini bir arada tutan sosyal tutkal işlevi görmesidir (O'Reilly ve Chatman, 1996: 160; Schein, 1996: 231; Goffee ve Jones, 2002: 28; Lapina vd., 2015: 771). Dolayısıyla örgüt kültürünü "örgütü bir arada tutan ve örgüt üyelerine yardımcı olan paylaşılan değerler dizisi” (Ertaş, 2017: 36) şeklinde tanımlamak mümkündür.

Ogbonna ve Harris (2000: 766-788), farklı örgüt kültürlerini inceledikleri araştırmalarında, Deshpande vd. (1993: 23-37) tarafından değerler esas alınarak geliştirilmiş örgüt kültürü türlerinin (klan, hiyerarşi, adokrasi, pazar) günümüz örgüt teorilerine uygun olduğu sonucuna varmışlardır. Bu sonuçta, örgüt yöneticileriyle yapılmış görüşmeler sonucunda, Deshpande vd.'nin (1993) örgüt kültürünün yöneticilerin görüşleriyle de uyumlu olduğunun görülmesi, etkili olmuştur (Ogbonna ve Harris, 2000: 773). Söz konusu örgüt kültürü Ogbonna ve Harris (2000: 772-773) tarafından "bürokratik", "rekabetçi", "toplumcu" ve "yenilikçi" olarak yeniden isimlendirmiştir.

Bürokratik kültüre göre, örgütler durağan olmalı, mal ve/veya hizmetleri ise istikrarlı olmalıdır. Bu kültür türünde, başarılı olabilmek için, standartlaşmış kuralları ve prosedürleri, kontrol ve sorumlu mekanizmaları uygulamak gerekmektedir (Valencia vd., 2016: 32). Dolayısıyla bu tür örgütlerde çalışanlar, standart kurallara göre hareket etmektedir. Bürokratik kültürde, işlerin yapılmasında herhangi bir sorun çıkmasına müsaade edilmez (Hooijberg ve Petrock, 1993: 31). Öte yandan bu kültürde, çalışanlardan ziyade üstlenilen rollere önem verilmektedir (Erdem vd., 2010: 80). Nitekim çalışanlardan, örgüte ekstra bir şey katmaktan ziyade (Zahedipour ve Haghighi, 2015: 119), sadece üstlenmiş oldukları rolleri yerine getirmeleri istenmektedir (Ergün, 2007: 268). Daha açık bir şekilde ifade etmek gerekirse, bürokratik kültür, çalışanlarından itaat beklemektedir (Güler, 2005: 28-29). Özetle, bürokratik kültürün temel özellikleri, "disiplinin öncelikli unsur olması" ve "insanın örgütün ana unsuru olarak pek önemsenmeyip daha çok bir araç olarak görülmesi” şeklinde açıklanabilir (Zahedipour ve Haghighi, 2015: 120).

Rekabetçi kültürde temel değerler, rekabet edebilirlik ve verimliliktir (Cameron ve Freeman, 1991: 26). Dolayısıyla, bu kültürde üretimin önemli bir unsur olduğunu söylemek mümkündür. Çalışanlar ise bu üretime yaptıkları katkılara göre değerlendirilmektedir (Erdem vd., 2010: 80; Ergün, 2007: 269). Rekabetçi kültürde bir diğer önemli nokta, örgüt içi ilişkiler yerine diş çevreyle (tedarikçiler, müşteriler, birlikler ve yönetmelikler gibi) kurulacak ilişkilere önem verilmesidir (Cameron ve Quinn, 2006: 40). Nitekim bu kültürde, bireyler birbirine rakiptir ve amaç odaklı hareket etmektedir (Tütüncü ve Akgündüz, 2012: 62).

Toplumcu kültür, rekabetçi kültürün tam tersi özelliklere sahiptir (Deshpande vd., 1993: 26). Örneğin bu kültür türünde, öncelikle çalışanların mutluluğu önemsenmektedir (Cameron ve Quinn 2006: 41). Öte yandan, çalışanlar yönetimin alacağı kararlara katılmaları için teşvik edilirler. Zaten bu kültürü benimsemiş örgütlerde yöneticilerin asıl görevi de, çalışanların kararlara katılımlarını sağlamaktır (Tütüncü ve Akgündüz, 2012: 62). Toplumcu kültürü benimsemiş örgütlerde, iş ortamından öte bir aile havası söz 
konusudur (Guner, 2001: 73). Bu örgütlerin yöneticileri ise, bu ailenin reisi gibi hareket eder (Hooijberg ve Petrock, 1993: 30) ve onların ihtiyaçlarını giderir (Vilkinas ve Cartan, 2006: 507).

Yenilikçi kültürde, çalışanlar yenilikleri takip etmeleri için teşvik edilirler (Darvish ve Nazari, 2013: 4). Dolayısıyla yenilikçi bir kültürü benimsemiş örgütlerdeki yöneticilerin esas görevi de, çalışanlarının girişimciliğine ve yaratıcılığına destek olmaktır (Hooijberg ve Petrock, 1993: 31). $\mathrm{Bu}$ kültürün öncelikli değerleri; girişimcilik ve yaratıcılıktır (Cameron ve Freeman, 1991: 27; Deshpande vd., 1993: 26; Cameron ve Quinn, 2006: 45). Bunlara ek olarak, çalışanları güçlendirme ve kararlara katılım konusunda teşvik etme, yenilikçi kültürün temel değerleri arasındadır (Valencia vd., 2016: 33). Yenilikçi kültürde, bürokratik ve rekabetçi kültürün aksine, hiyerarşi bulunmamaktadır (Cameron ve Quinn, 2006: 44).

\section{Yöntem}

Araştırmanın anakütlesi; Güneydoğu Anadolu Bölgesi'nde faaliyet gösteren turizm işletme belgeli 5 yıldızlı otellerde üst düzey yönetici pozisyonu dişındaki çalışanlardır. Kültür ve Turizm Bakanlığı Yatırım ve İşletmeler Genel Müdürlüğ̈̈'nün (2017) sitesindeki verilere göre Güneydoğu Anadolu Bölgesi'nde 13 adet 5 yıldızlı otel statüsünde işletme bulunmaktadır. Fakat bu oteller arasında bulunan The Green Park Diyarbakır'ın kapandığı tespit edilmiştir. Dolayısıyla araştırma anakütlesinin belirlenmesinde 12 otel esas alınmıştır. $\mathrm{Bu}$ otellerdeki toplam çalışan sayısı bilinmemektedir. $\mathrm{Bu}$ konuda çeşitli kurumlarla kurulan iletişim sonucunda da bir bilgi edinilememiştir. Ancak bu araştırma yazarının yapmış olduğu doktora tezi (bkz. Ertaş, 2017) sonucunda, 5 yıldızlı otellerde odabaşına 0,9 personel düştüğü tespit edilmiştir. Bu araştırmada da, ilgili otellerdeki çalışan sayısının tespit edilmesinde bu veri esas alınmıştır. $\mathrm{Bu}$ amaçla, öncelikle söz konusu oteller aranarak ya da internet siteleri incelenerek, sahip oldukları oda sayısına bakılmıştır. Sonuç olarak, Güneydoğu Anadolu Bölgesi'ndeki 5 yıldızlı 12 otelde, toplamda 1870 adet oda bulunduğu sonucuna ulaşılmıştır. Odabaşına düşen 0,9 personel tespitinden yola çıkarak, Güneydoğu Anadolu Bölgesi'ndeki ilgili otellerde 1683 çalışan bulunduğu söylenebilir. Dolayısıyla anakütle büyüklüğü (N) 1683 kişi olarak belirlenmiştir.

\subsection{Veri Toplama Arac1}

$\mathrm{Bu}$ araştırmada veri toplama aracı olarak, anket kullanılmıştır. Kullanılan anket formu, toplam iki bölümden oluşmaktadır. Birinci bölümde, katılımcıların bazı demografik özelliklerine ve çalıştıkları birime ilişkin, katılımcılara yöneltilen altı soru bulunmaktadır. Anketin ikinci bölümünde ise, 23 maddelik örgüt kültürü ölçeği yer almaktadır.

Araştırmada örgüt kültürünü ölçmek için, Ogbonna ve Harris (2000) tarafindan Deshpande vd.'nin (1993) çalışması uyarlanarak geliştirilmiş örgüt kültürü ölçeği kullanılmıştır. İlgili ölçek, Quinn'ın (1988) ve Campbell ve Freemann'ın (1991) önceki çalışmalarına dayanmakta ve teorik bakımdan örgüt kültürüne dönük diğer ölçeklerden daha üstün olarak görülmektedir. Tüm bunlara ek olarak, ilgili ölçek daha öz ve uygulanması kolaydır (Ogbonna ve Harris, 2000: 773).
Ölçeğin geliştirilme aşamasında, ölçek güvenilirlik ve geçerlilik açısından yeterli psikometrik özellikler göstermiş; araştırmacılar tarafından yapılan analizler sonrasında, bürokratik kültür boyutunun 0,702, rekabetçi kültür boyutunun 0,769 , toplumcu kültür boyutunun 0,669 , yenilikçi kültür boyutunun ise 0,764 düzeyinde güvenilir olduğu tespit edilmiştir (Ogbonna ve Harris, 2000: 778). Ölçek; bürokratik kültür, rekabetçi kültür, toplumcu kültür ve yenilikçi kültür olmak üzere dört boyuttan; yedisi bürokratik kültür, beşi rekabetçi kültür, altısı toplumcu kültür ve beşi yenilikçi kültür maddesi olmak üzere toplam 23 maddeden oluşmaktadır. Ölçeğin yanıt kategorileri 5'li derecelemeye tabi tutulmuştur (1: Kesinlikle Katılmıyorum, .. 5: Kesinlikle Katılıyorum). Ölçeğin orijinal hali 22 maddeden oluşmaktadır. Ancak orijinal ölçekteki birinci ölçek maddesi "işletmemizde istikrar ve değişmezlik önemlidir” şeklindedir. Fakat istikrar ve değişmezliğin ayrı kavramlar olduğu, bir arada kullanılırsa katılımcı tarafından yanlış anlaşılabileceği düşüncesiyle, ilgili madde ikiye ayrılmıştır. Dolayısıyla bu araştırmada ilgili ölçek 23 maddeden oluşmaktadır. Ölçeğin geçerliliği ve güvenilirliği, Tütüncü ve Akgündüz (2012) tarafindan yapılan araştırmayla da sağlanmıştır.

Araştırma verileri, 20 Kasım 2017-15 Mart 2018 tarihleri arasında toplanmış ve toplamda 246 (n) katılımcıya ulaşılmıştır. Araştırmanın anakütlesi dikkate alındığında, araştırmanın örneklem sayısının yeterli olduğu söylenebilir (Yazıcıŏlu ve Erdoğan, 2004: 50).

\section{2. İşlem}

Araştırma için toplanan anketlerin tamamı araştırmacı tarafından incelenmiş, eksik doldurulan veya özensiz işaretlenen olası anketlerin olup olmadığına bakılmıştır. Yapılan işlem sonucunda, elde edilen tüm anketlerin kullanılabilir durumda olduğu tespit edilmiştir. Daha sonra, olası çok yönlü uç değerleri tespit etmek ve veri setinden çıkarmak amacıyla, veri setine sapan analizi uygulanmıştır (Çokluk vd., 2010: 42). Yapılan analiz sonucunda, verilere ilişkin $t$ değerinin (tmax) 2,86 olduğu ve $t$ dağılımlarının \%o1 anlam düzeyinde kritik t değeri olan 3,767'den (veri setindeki madde sayısı: 23) (Büyüköztürk, 2016: 202) düşük olduğu tespit edilmiştir. Dolayısıyla, veri setinde sapan değer bulunmadığ 1 görülmüştür. $\mathrm{Bu}$ işlemin sonrasında, veri setinin çok değişkenli istatistiksel analize uygun olup olmadığını tespit etmek amacıyla, değişkenlere ilişkin veri setine çok değişkenli normal dağılım testi uygulanmıştır. Yapılan analiz sonucunda, veri seti için bulunan mahalanobis uzaklıkları ile ters birikimli ki-kare değerleri arasındaki korelasyon katsayısı 0,984'tür. 0,005 anlam düzeyinde ve 23 serbestlik derecesinde kritik korelasyon katsayıs1 ise 0,922'dir (Kalayc1, 2016: 231). Dolayısıyla, değişkenlerin normal dağılım gösterdiği görülmüştür (Kalaycı, 2016: 215). Bu bulgu, değişken çiftleri arasındaki ilişkinin doğrusal olduğuna da işaret etmektedir (Çokluk vd., 2010: 210).

Toplam 23 maddeden oluşan örgüt kültürü ölçeğinin tamamı için Cronbach's Alpha katsayısı 0,955'tir. Bu sonuç, ölçeğin çok yüksek derecede güvenilir olduğunu göstermektedir (Özdamar, 2011: 605). Örgüt kültürü ölçeğindeki 23 maddenin her birinin, ölçeğin toplamından oluşan bütün ile arasındaki korelasyonların 0,25 değerinin üzerinde olduğu 
tespit edilmiştir. $\mathrm{Bu}$ değerler ölçeği oluşturan her bir maddenin ölçeğin tamamına yaptığı katkının kabul edilebilir sınırlar içerisinde olduğunu göstermektedir (Kalayc1, 2016: 412). Dolayısıyla bu analize göre, ölçekten silinmesi gereken bir madde görülmemektedir.

Güvenilirlik analizinden sonra, yapı geçerliliği analizi aşamasına geçilmiştir. Araştırmada kullanılan örgüt kültürü ölçeğinin yap1 geçerliliğinin test edilmesi amacıyla, açıklayıcı faktör analizi uygulanmıştır. Ancak açıklayıcı faktör analizinden önce örneklem büyüklüğünün faktörleşmeye uygun olup olmadığını kontrol etmek amacıyla Kaiser-Meyer-Olkin (KMO) testi yapılmıştır. Test sonucunda KMO örneklem yeterliliği değeri 0,944 olarak tespit edilmiştir. $\mathrm{Bu}$ bulgu, örneklem büyüklüğünün faktör analizi uygulaması için mükemmel derecede yeterli olduğunu göstermektedir (Çokluk vd., 2010: 207).

Açıklayıcı faktör analizi için; korelasyon katsayısının (güvenilirlik analizi sonuçlarında yer alan düzeltilmiş madde toplam korelasyonları) en az 0,30 olması (Şencan, 2005: 380 ), ortak varyansın (communality) en az 0,50 düzeyinde olması (Kalaycı, 2016: 329), öz değeri 1'in üzerinde olan maddelerin dikkate alınması, bir maddenin yük değerinin en az 0,50 olması, açıklanan varyans oranının en az $\% 40$ olması, faktörleştirme tekniği olarak temel bileşenler analizi kullanılması ve dik döndürme yöntemlerinden maksimum değişkenlik (Varimax) tercih edilmesi (Çokluk vd., 2010: 192-203) ön kabulleri dikkate alınmıştır.

Araştırmada son olarak, konaklama işletmeleri çalışanlarının örgüt kültürü algısının çalışanların çalıştıkları birimler itibariyle anlamlı bir farklılık gösterip göstermediğini tespit etmek amacıyla tek yönlü ANOVA testi yapılmıştır.

\section{Bulgular ve Yorumlar}

\subsection{Demografik Bulgular}

Araştırmada öncelikle, katılımcıların demografik ve çalışma yaşamına ilişkin bazı özelliklerini öğrenmek amacıyla birtakım soru sorulmuştur. Demografik özelliklerine ilişkin bilgiler Tablo 1'de verilmektedir.

Tablo 1. Örneklem Grubunun Bazı Demografik Özellikleri

\begin{tabular}{|c|c|c|c|}
\hline Demografik Özellikler & & $\mathrm{n}$ & $\begin{array}{c}\% \\
\text { (yaklaşık) }\end{array}$ \\
\hline \multirow{2}{*}{ Cinsiyet } & Kadın & 103 & 42,00 \\
\hline & Erkek & 143 & 58,00 \\
\hline \multirow{2}{*}{ Medeni Durum } & Evli & 97 & 39,00 \\
\hline & Bekâr & 149 & 61,00 \\
\hline \multirow{6}{*}{ Eğitim Düzeyi } & İlkokul & 15 & 6,00 \\
\hline & Ortaokul & 43 & 18,00 \\
\hline & Lise & 60 & 24,00 \\
\hline & Önlisans & 63 & 26,00 \\
\hline & Lisans & 62 & 25,00 \\
\hline & Yüksek Lisans & 3 & 1,00 \\
\hline \multirow{5}{*}{ Aylık Kişisel Gelir } & $1500 \mathrm{TL}$ ve alt1 & 23 & 9,00 \\
\hline & $1501-2000 \mathrm{TL}$ & 118 & 48,00 \\
\hline & $2001-2500 \mathrm{TL}$ & 87 & 35,00 \\
\hline & $2501-3000 \mathrm{TL}$ & 12 & 5,00 \\
\hline & 3001 TL ve + & 6 & 3,00 \\
\hline \multirow{2}{*}{ Yaş } & $18-30$ yaş arası & 153 & 62,00 \\
\hline & 31 yaş ve üzeri & 93 & 38,00 \\
\hline
\end{tabular}

Tablo 1 incelendiğinde, katılımcıların çoğunluğunun (\%58) erkek olduğu görülmektedir. Katılımcılar medeni durumları bakımından incelendiğinde, katılımcıların önemli bir kısmının (\%61) bekâr olduğu; eğitim durumu bakımından incelendiğinde ise, $\% 25$ 'sinin lisans, \%24'ünün ise lise mezunu olduğu görülmektedir. Öte yandan katılımcıların nerdeyse yarısının (\%48) aylık kişisel gelirinin 1501 TL2000 TL arasında olduğu, çoğunluğunun (\%62) ise 18-30 yaş aralığında bulunduğu anlaşılmaktadır. Ankette, yaş değişkeni kategorik olarak belirtilmemiştir. Ancak veri girişleri yapıldıktan sonra, yaş değişkeni "18-30 yaş arası" ve "31 yaş ve üzeri” şeklinde kategorik hale getirilmiştir. Genel olarak bu bulgulara dönük bir değerlendirme yapmak yerinde olacaktır. Araştırma kapsamındaki otellerin 5 yıldızlı olduğu düşünüldüğünde, bu otellerde çalışan lisans mezunu oranının lise mezunlarıyla nerdeyse aynı olması, eğitime verilen önem açısından düşündürücü bir bulgudur. Araştırma katılımcılarının ağırlıklı olarak bekârlardan ve gençlerden oluşması ise, turizm sektörünün bekâr ve gençlerin çalıştığı bir sektör olduğu yönündeki genel inancı (Ertaş ve Unur, 2017: 247) destekler niteliktedir.

Katılımcıların hangi birimde çalıştıklarına dönük bir soru bulunmaktadır. Bu soruyu önbüro, servis veya kat hizmetleri olarak yanıtlayan katılımcılar önemsenebilecek bir sayıdadır. Ancak diğer birimler tek tek ele alındığında, katılımcıların sayısı karşılaştırma yapabilmek açısından yetersiz düzeydedir. Dolayısıyla sağlıklı karşılaştırmalar yapabilmek için, insan kaynakları, muhasebe, pazarlama gibi birimlerde çalıştığını ifade eden katılımcılar "diğer" olarak tek grup haline getirilmiştir. Katılımcıların çalıştıkları birime ilişkin bilgiler Tablo 2'de verilmektedir.

Tablo 2. Katılımcıların Çatıştıkları Birim

\begin{tabular}{llll}
\hline Birim & & $\mathrm{n}$ & \% (yaklaş1k) \\
\hline \multirow{3}{*}{ Cinsiyet } & Önbüro & 73 & 30,00 \\
\cline { 2 - 4 } & Servis & 84 & 34,00 \\
\cline { 2 - 4 } & Kat Hizmetleri & 36 & 14,00 \\
\cline { 2 - 4 } & Diğer & 53 & 22,00 \\
\hline
\end{tabular}

Tablo 2 incelendiğinde, katılımcıların toplamda \%64'ünün önbüro ve servis birimlerinde, \%22'sinin ise diğer birimlerde çalıştığı görülmektedir. Bu bulgu, konaklama işletmelerinde çalışanların önemli bir kısmının ön büro ve servis birimlerinde çalıştığ 1 şeklinde yorumlanabilir.

\subsection{Açıklayıcı Faktör Analizi}

Örgüt kültürü ölçeğine uygulanan ilk faktör analizi sonucunda, 11. (otelimizde yoğun çalışmayı seven yöneticiler, en iyi yöneticilerdir) sıradaki ölçek maddesinin ortak varyansının 0,50 'nin altında olduğu tespit edilmiştir. Dolayısıyla ilgili madde ölçekten çıkarılarak, kalan 22 maddeye tekrar faktör analizi uygulanmıştır. Ancak bu kez, 7. (otelimizde yazılı kurallar çoktur) ve 12. (otelimizin rekabet gücünü artıracak faaliyetler, bizi bir arada tutar) sıradaki ölçek maddelerinin hem binişik durumda olduğu, hem de olması gereken boyutların dışındaki boyutlar altında yer aldığı görülmüştür. Dolayısıyla bu maddeler de analizden çıkarılmıştır. Kalan 20 ölçek maddesi için uygulanan faktör analizinde, bütün ön kabuller karşılanmış ve öz değeri 1'in üzerinde olan üç faktör tespit edilmiştir. Bu üç faktörün toplam varyansa yaptığı katkı oranı $\% 64,203$ 'tür. 
Açıklayıcı faktör analizi sonuçları, Tablo 3'te özetlenmektedir.

Tablo 3. Örgüt Kültürü Ölçeğine İlişkin Açıklayıcı Faktör Analizi Özeti

\begin{tabular}{|c|c|c|c|}
\hline $\begin{array}{l}\text { Faktörler ve } \\
\text { Maddeleri }\end{array}$ & & O. V. & F. Y. \\
\hline \multirow{9}{*}{$\begin{array}{l}\text { Bürokratik } \\
\text { Kültür } \\
\text { ( } 9 \text { madde) }\end{array}$} & Otelimizde, değişmezlik önemlidir. & 0,732 & 0,803 \\
\hline & Otelimiz, bürokratiktir. & 0,676 & 0,749 \\
\hline & Otelimizde, istikrar önemlidir. & 0,723 & 0,738 \\
\hline & $\begin{array}{l}\text { Otelimizde, gelenekler bizleri bir } \\
\text { arada tutan değerlerdir }\end{array}$ & 0,640 & 0,724 \\
\hline & $\begin{array}{l}\text { Otelimizde, işlerin sorunsuz olarak } \\
\text { sürdürülmesi önemlidir. }\end{array}$ & 0,602 & 0,714 \\
\hline & $\begin{array}{l}\text { Otelimizde, rekabet her zaman ön } \\
\text { plandadır. }\end{array}$ & 0,570 & 0,672 \\
\hline & $\begin{array}{l}\text { Rekabet avantajı sağlamak, } \\
\text { otelimizin önemli değerleri } \\
\text { arasındadır. }\end{array}$ & 0,537 & 0,650 \\
\hline & $\begin{array}{l}\text { Otelimizde, kişisel ilişkilerden } \\
\text { ziyade, rekabet avantajı } \\
\text { kazandıracak işlere önem verilir. }\end{array}$ & 517 & 0,600 \\
\hline & $\begin{array}{l}\text { Otelimizde, kurallara bağlılık çok } \\
\text { önemlidir. }\end{array}$ & 0,552 & 0,594 \\
\hline \multirow{5}{*}{$\begin{array}{l}\text { Yenilikçi } \\
\text { Kültür } \\
\text { (5 Madde) }\end{array}$} & Otelimiz, yenilikçidir. & 0,760 & 0,795 \\
\hline & $\begin{array}{l}\text { Otelimizde, yenilikçi olan } \\
\text { yöneticiler en iyi yöneticiler olarak } \\
\text { kabul edilir. }\end{array}$ & 0,698 & 0,762 \\
\hline & Otelimiz, dinamiktir. & 0,747 & 0,726 \\
\hline & $\begin{array}{l}\text { Otelimizin yenilikçi olması, bizi bir } \\
\text { arada tutmaktadır. }\end{array}$ & 0,708 & 0,718 \\
\hline & $\begin{array}{l}\text { Otelimizde, yeni görüşlerin } \\
\text { değerlendirilmesine önem verilir. }\end{array}$ & 0,580 & 0,637 \\
\hline \multirow{6}{*}{$\begin{array}{l}\text { Toplumcu } \\
\text { Kültürü } \\
\text { (6 Madde) }\end{array}$} & $\begin{array}{l}\text { Otelimizde, çalışanların moral } \\
\text { seviyesinin yükseltilmesine önem } \\
\text { verilir. }\end{array}$ & 0,692 & 0,747 \\
\hline & $\begin{array}{l}\text { Sadakat, otelimizi bir arada tutan } \\
\text { önemli değerler arasındadır. }\end{array}$ & 0,707 & 0,741 \\
\hline & $\begin{array}{l}\text { Otelimizde, çalışanlar arasında } \\
\text { sosyal ilişkilerin artırılması } \\
\text { önemlidir. }\end{array}$ & 0,664 & 0,728 \\
\hline & $\begin{array}{l}\text { Otelimizde, geleneklere uygun } \\
\text { davranışlarda bulunmak önemlidir. }\end{array}$ & 0,589 & 0,618 \\
\hline & Otelimiz, büyük bir aile gibidir. & 0,603 & 0,586 \\
\hline & $\begin{array}{l}\text { Otelimizde, astlarına anne/baba } \\
\text { yaklaşımıyla davranan yöneticiler } \\
\text { en iyi yöneticilerdir. }\end{array}$ & 0,545 & 549 \\
\hline
\end{tabular}

Varimax Rotasyonlu Temel Bileşenler Analizi - Açıklanan toplam varyans: \%64,203; KMO Örneklem Yeterliliği: 0,941 - Bartlett Küresellik Testi: $\mathrm{X}^{2}: 3323,301$ s.d.: $190 \mathrm{p}<0.001$;

Genel Ortalama: 3,484 - Ölçeğin Tamamı için Alfa: 0,949;

Yanıt kategorileri: (1) Kesinlikle Katılmıyorum (2) Katılmıyorum (3) $\mathrm{Ne}$ Katıliyorum $\mathrm{Ne}$ Katılmıyorum (4) Kat1liyorum (5) Kesinlikle Katıliyorum

O.V. = Ortak Varyans; F.Y. = Faktör Yükü

Ortaya çıkan üç faktör, açıklanan toplam varyansa yaptıkları katkının önemi açısından değerlendirildiğinde, en yüksek katkının bürokratik kültür $(\% 26,494)$, en düşük katkının ise toplumcu kültür $(\% 16,730)$ tarafindan yapıldı̆̆ edilmiştir. Yenilikçi kültürün ise, \%20,979 oranında katkıda bulunduğu görülmüştür. Açıklayıcı faktör analizi sonucunda, yazındaki yapıdan farklı olarak, bürokratik kültür ile rekabetçi kültür faktörlerinin tek faktör altında birleştiği dikkati çekmektedir ve bu faktör dokuz maddeden oluşmaktadır. $\mathrm{Bu}$ faktör altındaki majör maddelerin bürokratik kültürü oluşturan maddeler olduğu görülmüştür.
Öte yandan ikinci faktör, beş maddeden oluşmaktadır ve maddeler incelendiğinde, faktörün "yenilikçi kültür” ile ilgili olduğu görülmektedir. Üçüncü faktör de, altı maddeden oluşmaktadır ve maddeler incelendiğinde, faktörün “toplumcu kültür" ile ilgili olduğu görülmektedir. Faktör ortalamaları arasında çok uçuk farklar olmasa da, araştırmaya katılanların birinci faktör olan bürokratik kültüre en yüksek ortalamayı $(3,511)$, ikinci faktör olan yenilikçi kültüre en düşük ortalamayı $(3,431)$; toplumcu kültüre ise 3,488 ortalama verdiği tespit edilmiştir. Böylece Güneydoğu Anadolu Bölgesi'ndeki 5 yıldızlı konaklama işletmelerinin örgüt kültürü tespit edilmiş ve bu araştırmanın ilk sorusu yanıt bulmuştur. Son olarak; ortaya çıkan üç faktör güvenilirlik açısından incelendiğinde; bürokratik kültürün 0,917, yenilikçi kültürün 0,898 , toplumcu kültürün ise 0,871 oranında güvenilirliğe sahip olduğu görülmüştür. Dolayısıyla üç faktörün de çok iyi düzeyde güvenilirliğe sahip olduğunu söylemek mümkündür.

\subsection{Tek Yönlü ANOVA}

Sonraki aşamada, tespit edilen örgüt kültürü boyutlarının çalışanların çalıştıkları birimlere göre anlamlı farklılık gösterip göstermediğine geçilmiştir. Bu amaçla, tek yönlü ANOVA (One-Way ANOVA) yapılmıştır. Tek yönlü ANOVA'nın temel varsayımı, varyansların homojenliğidir ve varyansların homojen olduğunu söylemek için p değerinin 0.05 'ten büyük olması gerekmektedir (Kalaycı, 2016: 138). Yapılan varyansların homojenliği testinde $p$ değeri, bürokratik örgüt kültürü için 0,731 , yenilikçi örgüt kültürü için 0,452, toplumcu örgüt kültürü için ise 0,124'tür. Dolayısıyla, varyans analizinin temel varsayımı sağlanmıştır. Böylece varyans analizinde elde edilen sonuçların sağlıklı olduğunu söylemek mümkündür. Yapılan analiz sonuçları Tablo 4'te özetlenmiştir.

Tablo 4. Algılanan Örgüt Kültürü Boyutlarının Çalışılan Birime Göre Tek Yönlü ANOVA Testi Sonuçları

\begin{tabular}{|c|c|c|c|c|c|c|}
\hline Alt Boyut & Birim & $\mathrm{N}$ & Ort. & S. Sapma & $\mathrm{F}$ & $\mathrm{p}$ \\
\hline \multirow{4}{*}{ Bağlam } & Önbüro & 73 & 3,50 & 0,932 & \multirow{4}{*}{0,116} & \multirow{4}{*}{0,951} \\
\hline & Servis & 84 & 3,53 & 0,868 & & \\
\hline & Mutfak & 53 & 3,45 & 0,919 & & \\
\hline & Kat Hizmetleri & 36 & 3,54 & 0,796 & & \\
\hline \multirow{4}{*}{ Girdi } & Önbüro & 73 & 3,43 & 0,86 & \multirow{4}{*}{0,233} & \multirow{4}{*}{0,874} \\
\hline & Servis & 84 & 3,49 & 1,02 & & \\
\hline & Mutfak & 53 & 3,36 & 0,97 & & \\
\hline & Kat Hizmetleri & 36 & 3,37 & 0,97 & & \\
\hline \multirow{4}{*}{ Süreç } & Önbüro & 73 & 3,43 & 0,92 & \multirow{4}{*}{0,457} & \multirow{4}{*}{0,713} \\
\hline & Servis & 84 & 3,51 & 1,02 & & \\
\hline & Mutfak & 53 & 3,42 & 0,77 & & \\
\hline & Kat Hizmetleri & 36 & 3,62 & 0,79 & & \\
\hline
\end{tabular}

Tablo 4’te görüldüğü üzere; örgüt kültürünü oluşturan üç faktörde de, çalışılan birimler itibariyle ortalamalar birbirine çok yakındır ve herhangi bir farklılık bulunmamaktadır. Dolayısıyla, bu araştırma kapsamındaki konaklama işletmeleri çalışanları örneğinde, örgüt kültürü algısı çalışılan birime göre anlamlı bir farklılık göstermemiştir. Böylece, bu araştırmanın ikinci sorusu da yanıt bulmuştur.

\section{Sonuç ve Öneriler}

$\mathrm{Bu}$ araştırmada, konaklama işletmelerinin çalışanları tarafından algılanan örgüt kültürü ve bu algının çalışılan 
birime göre anlamlı bir farklılık gösterip göstermediği incelenmiştir. $\mathrm{Bu}$ amaçla, öncelikle çalışanların örgüt kültürü algısı tespit edilmiş, daha sonra bu alg1 çalışılan birime göre karşılaştırılmıştır. Araştırma bulgularına göre, ortalamaları açısından gözle görülür farklar olmasa da, Güneydoğu Anadolu Bölgesi'ndeki 5 yıldızlı otellerde çalışanlar, örgütlerinin kültürlerini "bürokratik" olarak algılamaktadır. Bu araştırma yazarının araştırmacılarından biri olduğu ve Ankara, İstanbul, Antalya ve İzmir'deki 5 yıldızlı otel çalışanları örnekleminde yapılmış araştırma (Ertaş ve Unur, 2017) sonucunda da, katılımcıların bürokratik örgüt kültürüne daha yüksek ortalama verdiği tespit edilmiştir. Aynı şekilde, Gün ve Derin (2017) tarafından Doğu ve Güneydoğu Anadolu Bölgesi'ndeki 4 ve 5 yıldızlı otellerde çalışanlar üzerine yapılmış bir araştırmada, katılımcıların en yüksek ortalamayı bürokratik örgüt kültürüne verdikleri görülmüștür. $\mathrm{Bu}$ bulgular, günümüzde sürekli gelişimi ve değişimi gerektiren konaklama işletmeleri için düşündürücüdür. Bürokratik örgüt kültürü, istikrarlı pazarlarda faaliyet gösteren örgütler için uygun bir kültür tipi olabilir (Wallach, 1983: 32). Turizm sektörü ise, kaçınılmaz olarak sürekli yeniliklere açıktır ve değişebilmektedir. Zira her geçen gün tüketici talepleri değişmekte ve bu da turizm işletmelerinin yenilikleri takip etmesini zorunlu hale getirmektedir. Konaklama işletmelerinin sürdürülebilirliği açısından düşünüldüğünde, bu yeniliklere uyum sağlamaları önem arz etmektedir. Her şeyden öte, yeniliklerin ve dolayısıyla değişimin gerisinde kalmamak, özellikle günümüzdeki örgütler için önemli bir husustur (Aksay, 2011: 78). Yenilikçi örgüt kültürünün, örgütlere birçok faydası bulunmaktadır. Örneğin Zhou vd.'nin (2005: 1056) araştırmasında, yenilikçi bir kültürü benimseyen örgütlerde, çalışanların örgütün geleceğine dönük güvenini artırdığ tespit edilmiştir. Öte yandan Wei vd. (2013: 1027-1041) yapmış oldukları araştırmada, yenilikçi bir örgüt kültüründe, çalışanların iş tatmini gibi çeşitli örgütsel davranışlarının olumlu yönde geliştiğini bulgulamıştır. Benzer yorumları, toplumcu örgüt kültürü için de yapmak mümkündür. Turizm gibi insan ilişkilerinin ve ekip çalışmasının yoğun olduğu bir sektörde, örgüt içi ilişkileri önemsemeyen bürokratik ve rekabetçi kültürden ziyade, bir aile ilişkisinin söz konusu olduğu toplumcu kültürü benimsemek, hem örgütlerin geleceği hem de çalışanların memnuniyeti açısından önemlidir.

$\mathrm{Bu}$ çalışmanın kavramsal kısmında verilen bilgilerden hareketle, bürokratik kültüre sahip örgütlerde, değişimden ziyade durağanlığın söz konusu olduğunu söylemek mümkündür. Öte yandan, bu tür örgütlerde, çalışanların kendisini değersiz hissetmesi ve mutsuz olması muhtemeldir. Bu mutsuzluk durumu ise, çalışanların birçok örgütsel davranışını olumsuz yönde etkileyecektir. Öyle ki Gün ve Derin (2017: 378) yapmış oldukları araştırmada, bürokratik örgüt kültürünün, kariyer yönetimi gibi değişkenler üzerinde olumsuz bir etkide bulunduğunu tespit etmiştir. Dolayısıyla, değişimin ve gelişimin büyük önem arz ettiği konaklama işletmelerinin bürokratik kültürü terk etmesinin, gerek örgütlerin sürdürülebilirliği gerekse çalışma yaşamı kalitesi açısından bir gereklilik olduğunu söylemek, yanlış olmayacaktır. Tüm bunlara ek olarak, bu araştırma sonucunda çıkan bürokratik örgüt kültürü algısının sebeplerinin derinlemesine incelenmesi ihtiyacı ortaya çıkmıştır. Ayrıca, rekabetçi kültür bürokratik kültürden farklı nitelikleri içermesine (Aksay, 2011: 75-76) rağmen, bu araştırma katılımcılarının bürokratik kültürle rekabetçi kültürü aynı başlık altında toplamış olması, dikkat çekici bir sonuçtur. Katılımcıların her iki kültür türünü de otoriter olarak algılamış olması, bu sonucun bir sebebi olabilir.

Bu araştırmada, çalışılan birimler itibariyle, örgüt kültürüne dönük algıda bir farklılık tespit edilmemiştir. Ancak farklı bir örgüt kültürü ölçeğinin kullanıldığı Rızaoğlu ve Ayyıldız'ın (2008) araştırmasında, çalışılan birimin örgüt kültürü üzerinde anlamlı bir etkisi tespit edilmiştir. Dolayısıyla bu iki araştırma arasındaki tespitlerin çakışması, konunun araștırılmasını gerekli kılmaktadır. Bu durumun sebeplerinden biri, kullanılan ölçeklerin farklılık gösteriyor olması olabilir. Araştırmaların farklı bölgelerde yapılmış olması da, bu farklı tespitlerin bir sebebi olabilir. Zira farklı bölgedeki bireylerin, kültürel yapıları da farklı olabilmekte ve bu durum örgüt kültürü algısını etkileyebilmektedir. Öte yandan, bu araştırma kapsamındaki oteller şehir otelidir ve daha çok sadece konaklama ihtiyacını karşılayan bireyleri ağırlamaktadır. Bu durum da, bu otellerin, çalışanlarından sadece kuralları uygulamalarını istemelerine sebep olabilmektedir. Dolayısıyla işler, bir noktadan sonra rutin bir hal almaktadır. $\mathrm{Bu}$ da birimler arasındaki iş farklılığını ortadan kaldırabilmektedir.

Örgüt kültürüne dönük yapılan yazın incelemesi sonucunda, çalışılan birim ile örgüt kültürü arasındaki ilişkiyi incelemiş sınırlı sayıda araştırma tespit edilmişti. Bu anlamda, bu araştırma öncü araştırmalardan biri olarak turizm yazınındaki eksikliğin doldurulmasına yardımcı olacaktır. Ancak yine de bu araştırma, birtakım sınırlılığa sahiptir. Öncelikle bu araştırma sonuçları Güneydoğu Anadolu Bölgesi'nde faaliyet gösteren 5 yıldızlı otel çalışanları kapsamındadır. Dolayısıyla benzer bir araştırmanın Güneydoğu Anadolu Bölgesi'ndeki diğer yıldızlı otellerde yapılması önem taşımaktadır. Ayrıca bundan sonra yapılacak olan araştırmalarda daha büyük bir örneklem üzerinde çalışılarak, daha sağlıklı sonuçlar elde edilebilir. Öte yandan bu araştırmada örgüt kültürü algısının çalışılan birime göre farklılık göstermediği tespiti, gelecekte yapılacak araștırmalarla test edilmelidir. Ayrıca bu araştırmanın çalışılan birime göre karşılaştırma yapmasının temel sebebi, birim yöneticilerinin çalışanlarına davranışlarının örgüt kültürü algısı üzerinde de etkili olabileceği varsayımıydı. Dolayısıyla ileride yapılacak araştırmalarda liderlik ile örgüt kültürü arasındaki ilişkiye bakılabilir. Özetle gelecekte benzer araştırmaların, farklı bölgelerde ve örneklemlerde, diğer yıldızlı konaklama işletmelerinde, farklı veri analizi yöntemleriyle ve başka örgüt kültürü ölçekleriyle yapılması, daha genellenebilir sonuçlar elde edebilmek adına önem taşımaktadır.

\section{Kaynakça}

Akgündüz, Y., Akdağ, G., Güler, O., \& Sünnetçioğlu, S. (2015). İşten ayrılma niyeti ve aşırı rol yükünün otel çalışanlarının sosyal aylaklık davranışlarına etkisi. Dokuz Eylül Üniversitesi Sosyal Bilimler Enstitüsü Dergisi, 16(4), 515-536.

Aksay, K. (2011). Yenilikçilik kültürünün örgütsel yenilikçilik üzerine etkisi: Konya ilinde faaliyet gösteren özel hastanelerde bir uygulama. Doktora Tezi. Konya: Selçuk Üniversitesi. 
Barutçugil, İ. (2004). Stratejik insan kaynakları yönetimi. İstanbul: Kariyer Yayıncılık.

Büyüköztürk, Ş. (2016). Sosyal bilimler için veri analizi el kitabı. Ankara: Pegem Akademi.

Cameron, K. S., \& Quinn, R. E. (1999). Diagnosing and changing organizational culture. MA: Addison Wesley Longman.

Cameron, K.S., \& Freeman, S.J. (1991). Cultural congruence, strength, and type: Relationships to effectiveness. Research in Organizational Change and Development, 5, 23-58.

Cameron, K.S., \& Quinn, R.E. (2006). Diagnosing and changing organizational culture: Based on the competing values framework. San Francisco: JosseyBass.

Çokluk, Ö., Şekercioğlu, G., \& Büyüköztürk, Ş. (2010). Sosyal bilimler için çok değişkenli istatistik spss ve lisrel uygulamalart. Ankara: Pegem Akademi.

Darvısh, H., \& Nazarı, E.A. (2013). Organizational learning culture-the missing link between innovative culture and innovations (Case study: Saderat Bank of Iran). Economic Insights-Trends and Challenges, 2(1), 1-16.

Deshpande, R., Farley, J.U., \& Webster, F.E. (1993). Corporate culture, customer orientation, and innovativeness in Japanese firms: A quadrad analysis. Journal of Marketing, 57, 23-27.

Diker, O. (2014). Algllanan liderlik tarzları, örgüt kültürü ve örgütsel bağlllık ilişkisinin turizm endüstrisinde incelenmesi. Doktora Tezi, Eskişehir: Eskişehir Osmangazi Üniversitesi.

Durğun, S. (2006). Örgüt kültürü ve örgütsel iletişim.Yüzüncü Yll Üniversitesi Ĕ̌itim Fakültesi Dergisi, 3(2), 112-132.

Erdem, R. Adigüzel, O., \& Kaya, A. (2010). Akademik personelin kurumlarına ilişkin algıladıkları ve tercih ettikleri örgüt kültürü tipleri. Erciyes Üniversitesi İktisadi ve İdari Bilimler Fakültesi Dergisi, 36, 73-88.

Ergün, E. (2007). Kurum kültürünü analiz etmede Quinn ve Cameron'un rekabetçi değerler analizi. 15. Ulusal Yönetim ve Organizasyon Kongresi Bildiriler Kitab1, Sakarya: Sakarya Üniversitesi.

Ertaş, Ç. (2017). Kültürel değerlerin örgütsel adalet algısına etkisinde örgüt kültürünün aracılık rolü: Otel çalışanları örneği, Doktora Tezi, Mersin: Mersin Üniversitesi.

Ertaş, Ç., \& Unur, K. (2017). Otel çalışanlarının kültürel değerlerinin örgüt kültürüne etkisi. Journal of Current Researches on Business and Economics, 7(2), 229-256.

Goffee, R., \& Jones, G. (2002). Kurum Kültürü. (Çev.) Kutmandu, K., Ankara: Media Cat Kitapları.

Guner, B. (2001). Can organizational behavior explain the export intention of firms? The effects of organizational culture and ownership type. International Business Review, 10, 71-89.

Güler, S. (2005). Örgüt kültürü içinde cinsiyet ayrımcılığl ve kadınların işyerinde karşılaştıkları mesleki baskılar:
Trakya Bölgesi imalat sektöründe kadın çalışanlar üzerine bir araştırma. Doktora Tezi, Ankara: Ankara Üniversitesi.

Gün, G., \& Derin, N. (2017). Örgüt kültürü tiplerinin kariyer yönetimi uygulamalarına etkisi: Otel işletmelerinde araştırma. Adlyaman Üniversitesi Sosyal Bilimler Enstitüsü Dergisi, 25, 349-389.

Hartmann, A. (2006). The role of organizational culture in motivating innovative behaviour in construction firms. Construction Innovation, 6(3), 159-172.

Hofstede, G., Hofstede, G. J., \& Minkov, M. (2010). Cultures and organizations: Software of the mind. Berkshire, England: McGraw-Hill.

Hooijberg, R., \& Petrock, F. (1993). On cultural change: Using the competing values framework to help leaders execute a transformational strategy. Human Resource Management, 32(1), 29-50.

Kalaycı, Ş. (2016). SPSS uygulamalı çok değişkenli istatistik teknikleri. Ankara: Asil Yayınevi.

Kanten, P. (2014). İşyeri nezaketsizliğinin sosyal kaytarma davranışı ve işten ayrılma niyeti üzerindeki etkisinde duygusal tükenmenin aracılık rolü. Aksaray Üniversitesi Iktisadi ve İdari Bilimler Fakültesi Dergisi, 6(1), 11-26.

Köse, O. (2014). Örgüt kültürü ve örgütsel bă̆lılık arasındaki ilişkinin incelenmesi: Bir kamu kurumunda alan araştırması. Doktora Tezi. Sakarya: Sakarya Üniversitesi.

Kültür ve Turizm Bakanlığı Yatırım ve İşletmeler Genel Müdürlüğü (2017). Turizm işletme belgeli tesisler. (Erişim: 01.11.2017) http://www.ktbyatirimisletmeler.gov.tr/TR,9579/turizmtesisleri.html

Lapina, I., Kairiša, I., \& Aramina, D. (2015). Role of organizational culture in the quality management of university. Procedia-Social and Behavioral Sciences, 213, 770-774.

O’Reilly, C.A., \& Chatman, J.A. (1996). Culture as social control: Corporations, cults, and commitment. Research in Organizational Behavior, 18, 157-200.

Ogbonna, E., \& Harris, L.C. (2000). Leadership style, organizational culture and performance: Empirical evidence from UK companies. International Journal of Human Resource Management, 11(4), 766-788.

Özdamar, K. (2011). Paket programlar ile istatistiksel veri analizi 1. Eskişehir: Kaan Kitabevi.

Pettigrew, A. M. (1979). On studying organizational cultures. Administrative Science Quarterly, 24(4), 570581 .

Polat, M., \& Meyda, C. H. (2011). Örgüt kültürü bağlamında güç eğilimi ve örgütsel bağlılık ilişkisinde örgütsel özdeşleşmenin aracılık rolü. Atatürk Üniversitesi İktisadi ve İdari Bilimler Dergisi, 25(1), 153-170.

Rızaoğlu, B., \& Ayyıldız, T. (2008). Konaklama işletmelerinde örgüt kültürü ve iş tatmini: Didim örneği. Anatolia: Turizm Araştırmaları Dergisi, 19(1), 7-20. 
Schein, E.H. (1996). Culture: The missing concept in organization studies. Administrative Science Quarterly, 41(2), 229-240.

Schwartz, H., \& Stanley, M. D. (1981). Matching corporate culture and business strategy. Organizational Dynamics, 10(1), 30-48.

Škerlavaj, M., Song, L.H., \& Lee, Y. (2010). Organizational learning culture, innovative culture and innovations in South Koreans firms. Expert Systems with Applications, 37, 6390-6403.

Smircich, L. (1983). Concepts of culture and organizational analysis. Administrative Science Quarterly, 28(3), 339358.

Sünnetçioğlu, S., Korkmaz, H., \& Koyuncu, M. (2014). Konaklama işletmelerinde algılanan örgüt kültür tipinin çalışanların sosyal kaytarma davranışlarını algılamasına etkisi üzerine bir araştırma. Mustafa Kemal Üniversitesi Sosyal Bilimler Enstitüsü Dergisi, 11(28), 17-34.

Şencan, H. (2005). Sosyal ve davranışsal ölçümlerde güvenilirlik ve geçerlilik. Ankara: Seçkin Yayıncılık.

Tütüncü, Ö., \& Akgündüz, Y. (2012). Seyahat acentelerinde örgüt kültürü ve liderlik arasındaki ilişki. Anatolia: Turizm Araştırmaları Dergisi, 23(1), 59-72.

Valencia, J.C.N., Jimenez, D.J., \& Valle, R.S. (2016). Studying the links between organizational culture, innovation, and performance in Spanish companies. Revista Latinoamericana de Psicologia, 48(1), 30-41.

Vilkinas, T., \& Cartan, G. (2006). The integrated competing values framework: İts spatial configuration. Journal of Management Development, 25(6), 505-521.

Wallach, E.J. (1983). Individuals and organizations: The cultural match. By Training and Development Journal, $37(2), 28-36$.

Wei, Y., O’Neill, H., Lee, R.P., \& Zhou, N. (2013). The impact of innovative culture on individual employees: The moderating role of market information sharing. The Journal of Product Innovation Management, 30(5), 1027-1041.

Wiener, Y. (1988). Forms of values systems: A focus on organizational effectiveness and cultural change and maintenance. Academy of Management Review, 13(4), 534-545.

Yazıcığlu, Y., \& Erdoğan, S. (2004). SPSS uygulamal bilimsel araştırma yöntemleri. Ankara: Detay Yayıncılık.

Zahedipour, M., \& Haghighi, M. (2015). Investigating the correlation between the organizational participative and bureaucratic culture wite teachers job burnout. International Journal of Biology, Pharmacy and Allied Sciences, 4(8), 117-125.

Zhou, K.Z., Gao, G.Y., Yang, Z., \& Zhou, N. (2005). Developing strategic orientation in China: Antecedents and consequences of market and innovation orientations. Journal of Business Research, 58(8), 1049-1058. 